\title{
Combined caveolin-1 and epidermal growth factor receptor expression as a prognostic marker for breast cancer
}

\author{
YA-NAN LIANG ${ }^{1,2}$, YU LIU $^{2}$, LETIAN WANG $^{3}$, GUODONG YAO $^{4}$, XIAOBO $^{2}{ }^{2}$, \\ XIANGNING MENG ${ }^{5}$, FAN WANG ${ }^{6}$, MING LI $^{6}$, DANDAN TONG ${ }^{2}$ and JINGSHU GENG ${ }^{4,7}$ \\ ${ }^{1}$ College of Pharmacy, ${ }^{2}$ Department of Pathology, Harbin Medical University; \\ ${ }^{3}$ College of Bioinformatics Science and Technology; ${ }^{4}$ Department of Pathology, \\ The Third Affiliated Hospital of Harbin Medical University; ${ }^{5}$ Department of Medical Genetics; \\ ${ }^{6}$ School of Public Health; ${ }^{7}$ Department of Medical Genetics, Harbin Medical University, \\ Harbin, Heilongjiang 150081, P.R. China
}

Received December 20, 2015; Accepted July 27, 2017

DOI: $10.3892 / \mathrm{ol} .2018 .8533$

\begin{abstract}
Previous studies have indicated that caveolin-1 (Cav-1) is able to bind the signal transduction factor epidermal growth factor receptor (EGFR) to regulate its tyrosine kinase activity. The aim of the present study was to evaluate the clinical significance of Cav-1 gene expression in association with the expression of EGFR in patients with breast cancer. Primary breast cancer samples from 306 patients were analyzed for Cav-1 and EGFR expression using immunohistochemistry, and clinical significance was assessed using multivariate Cox regression analysis, Kaplan-Meier estimator curves and the log-rank test. Stromal Cav-1 was downregulated in $38.56 \%$ $(118 / 306)$ of tumor tissues, whereas cytoplasmic EGFR and Cav-1 were overexpressed in 53.92\% (165/306) and 44.12\% (135/306) of breast cancer tissues, respectively. EGFR expression was positively associated with cytoplasmic Cav-1 and not associated with stromal Cav-1 expression in breast cancer samples; however, low expression of stromal Cav-1 was negatively associated with cytoplasmic Cav-1 expression in total tumor tissues, and analogous results were identified in the chemotherapy group. Multivariate Cox's proportional hazards model analysis revealed that, for patients in the estrogen receptor (ER)(+) group, the expression of stromal Cav-1 alone was a significant prognostic marker of breast cancer. However, in the chemotherapy, human epidermal growth factor receptor 2 (HER-2)(-), HER-2(+) and ER(-) groups, the use of combined
\end{abstract}

Correspondence to: Dr Dandan Tong, Department of Pathology, Harbin Medical University, 157 Baojian Road, Nangang, Harbin, Heilongjiang 150081, P.R. China

E-mail: tongdd1977@163.com

Dr Jingshu Geng, Department of Pathology, The Third Affiliated Hospital of Harbin Medical University, 150 Haping Road, Nangang, Harbin, Heilongjiang 150081, P.R. China

E-mail: jingshugeng@me.com

Key words: breast cancer, caveolin-1, epidermal growth factor receptor, prognosis markers was more effective prognostic marker. Stromal Cav-1 has a tumor suppressor function, and the combined marker stromal Cav-1/EGFR expression was identified as an improved prognostic marker in the diagnosis of breast cancer. Parenchymal expression of Cav-1 is able to promote EGFR signaling in breast cancer, potentially being required for EGFR-mediated initiation of mitosis.

\section{Introduction}

Breast cancer is the most common female malignancy worldwide and its incidence increases annually $(1,2)$. The caveolin-1 (Cav-1) gene is a member of the caveolin gene family, which is located at chromosomal locus $7 \mathrm{q} 31.1(3,4)$, and encodes the Cav-1 protein, which is a principal component of plasma membrane caveolae $(5,6)$. Cav-1 is expressed in various breast cell types, including mammary gland epithelial cells, fibroblasts, adipocytes, endothelial cells and smooth muscle cells (7-9), and functions in tumorigenesis primarily through lipid transport, membrane transport, gene regulation and signal transduction (10). Its abnormal expression in breast cancer, where it is a putative tumor suppressor (11), is associated with the occurrence, progression and poor prognosis of breast cancer (12-14). Epidermal growth factor receptor (EGFR) interacts directly with the caveolin-scaffolding domain through a caveolin-binding sequence motif located in the intracellular kinase domain of the receptor $(5,15)$, and this interaction has been demonstrated to modulate EGFR-mediated signaling $(16,17)$.

Cav-1 mutation or abnormal expression is able to positively regulate the expression of EGFR $(15,18,19)$, which is overexpressed in $\sim 33 \%$ of breast cancers (20). Abnormal activation of EGFR often indicates poor prognosis and has a marked association with differentiation and metastasis of tumor cells (21-27). Importantly, EGFR is highly concentrated in caveolae membrane fractions and binds Cav-1 via a caveolin-binding motif of the kinase domain $(15,28,29)$.

Considering the prognostic capacity of EGFR in breast cancer, the wide expression of Cav-1 in numerous breast cancers and the association between them, the present study 
sought to use a combination approach analyzing two proteins as a combined prognostic marker for breast cancer, something which, to the best of our knowledge, has not previously been reported.

\section{Materials and methods}

Tissue microarray (TMA). Archived paraffin blocks of 306 female breast cancer tumor tissues and 50 adjacent normal tissues were obtained from The Third Affiliated Hospital of Harbin Medical University (Harbin, China) between January 2007 and December 2007 (age range, 27-82 years; median age, 49 years; operated). Tissue samples used in the present study were approved by The Hospital Ethics Committee for Ethical Review of Research Involving Human Subjects at Harbin Medical University. None of the patients in the present study received radiation or chemotherapy prior to the surgery that produced the paraffin-embedded tissues. Breast cancer TMAs created from each of the 356 total tissue samples were used for immunohistochemistry (IHC). Primary cancers were evaluated in accordance with the 7th edition of the American Joint Committee on Cancer tumor-node-metastasis (TNM) staging system (30). Estrogen receptor (ER) $(+)$, progesterone receptor $(\mathrm{PR})(+)$, human epidermal growth factor receptor $2($ HER-2) (+), p53 (+) and Ki-67 (+) patients were identified by a review of the pathological report. Median follow-up time for overall survival (OS) of 306 patients was 68.27 months (range, 3.85-75.02 months), and median follow-up time for disease-free survival (DFS) of 306 patients was 69.41 months (range, 2.14-75.02 months). Follow-ups for all patients continued until December 2013 or until mortality. The clinicopathological features of the 306 patients included are summarized in Table I.

IHC. Paraffin-embedded breast cancer TMA (Shanghai Outdo Biotech Co., Ltd.) sections ( $3 \mu \mathrm{m})$ were deparaffinized with pure xylene for $15 \mathrm{~min}$ and rehydrated in a descending alcohol series (from 70, 85 and 95\% until pure alcohol for $5 \mathrm{~min}$ ) at room temperature. The TMAs were subsequently submerged in citrate $\left(\mathrm{pH} \mathrm{6.0)}\right.$ and autoclaved at $120^{\circ} \mathrm{C}$ for $2 \mathrm{~min}$, then quenched with $3 \% \mathrm{H}_{2} \mathrm{O}_{2}$ for 10 min and blocked with $5 \%$ goat serum (OriGene Technologies, Inc., Beijing, China) for $10 \mathrm{~min}$ at room temperature. TMAs were cooled for $30 \mathrm{~min}$ prior to incubation with primary rabbit polyclonal antibody for Cav-1 (cat. no. 3238; dilution, 1:100; Cell Signaling Technology, Inc., Danvers, MA, USA) and a rabbit polyclonal instant antibody against EGFR (cat. no. YT1488; dilution, 1:200; Immunoway Biotechnology Company, Plano, TX, USA) overnight at $4^{\circ} \mathrm{C}$. Finally, TMAs were incubated with horseradish peroxidase-linked goat anti-rabbit secondary antibody (cat. no. PV6001; OriGene Technologies, Inc.) for $20 \mathrm{~min}$ at room temperature, the sections were then stained with DAB (OriGene Technologies, Inc.) to detect the proteins for $2 \mathrm{~min}$ at $37^{\circ} \mathrm{C}$, followed by counterstaining with hematoxylin for $5 \mathrm{~min}$ at $37^{\circ} \mathrm{C}$. Slides were dehydrated through an ascending series of alcohols (from 85 and $95 \%$ until pure alcohol for $5 \mathrm{~min}$ ) and mounted. IHC and scoring were performed using a light microscope at magnifications, x100 and x400, separately for all samples by two independent investigators without any prior knowledge of the clinicopathological data.
The degree of Cav-1 IHC staining was evaluated in tumor and stromal cells and scored semi-quantitatively. Cav-1 staining in tumor and stromal cells was scored semi-quantitatively as: 0 , no staining; 1 , either diffuse weak or focal strong staining in $<30 \%$ of cells; or 2 , strong staining of $\geq 30 \%$ cells (14). Comparison with endothelial cell staining intensity was used to assess the intensity of the immunoreactions and Cav-1 down-expression corresponded to grading scores 0 and 1 . IHC staining for EGFR was scored according to the following criteria: -, 0-5\%; +, 6-25\%; ++, 26-50\%; and +++, 51-100\% of the cells stained. To optimally balance the multitude of the two sides divided on the basis of the positive staining rate, a threshold of $25 \%$ was used for EGFR. Positive values indicate that the positive staining cell rates were increased compared with the threshold value, whereas negative values indicate the rate was decreased compared with or equal to the threshold value.

Statistical analysis. Statistical calculations were performed using the SPSS statistical software package (version 19.0; IBM SPSS, Armonk, NY, USA). P<0.05 was considered to indicate a statistically significant difference. Correlation between expression levels was determined using the Pearson coefficient. $\chi^{2}$ tests were used to analyze the association between Cav-1 and EGFR expression and clinicopathological features. Cumulative OS curves were generated according to the Kaplan-Meier estimator method, and the association between each of the variables and survival was assessed using the log-rank test in a univariate analysis. To identify independent predictors of survival, the parameters were then tested using the multivariate Cox's proportional hazards model.

\section{Results}

Expression of cytoplasmic EGFR and Cav-1 and stromal Cav-1 in breast cancer tissues. Using IHC, the expression of cytoplasmic EGFR and Cav-1 and stromal Cav-1 was detected in patient breast tumor and adjacent normal breast tissues. As presented in Fig. 1, cytoplasmic EGFR and Cav-1 were significantly overexpressed $(\mathrm{P}<0.001$ and $\mathrm{P}=0.007$, respectively) in tumor tissues relative to adjacent normal tissues, whereas stromal Cav-1 appeared to be downregulated $(\mathrm{P}=0.010)$. IHC analysis revealed that cytoplasmic EGFR and Cav-1 were overexpressed in $53.92 \%(165 / 306)$ and $44.12 \%$ $(135 / 306)$, respectively, of tumor tissues, whereas stromal Cav-1 was downregulated in $38.56 \%$ (118/306) of tumor tissues.

\section{Clinical significance of cytoplasmic EGFR and Cav-1} and stromal Cav-1 expression in breast cancer tissues. Downregulation of stromal Cav-1 in breast cancer was associated with differentiation $(\mathrm{P}=0.050), \mathrm{p} 53$ status $(\mathrm{P}=0.001)$ and Ki-67 status $(\mathrm{P}=0.042)$, but not with any of the other clinical parameters. Overexpression of cytoplasmic EGFR was positively associated with HER-2 $(\mathrm{P}=0.015)$ and Ki-67 $(\mathrm{P}=0.015)$ expression (data not shown). Statistical correlation analysis demonstrated that EGFR expression was positively correlated with cytoplasmic Cav-1 expression ( $\mathrm{r}=0.177$; $\mathrm{P}=0.002$ ), but no correlation with stromal Cav-1 expression in tumor tissues was identified; however, low expression of 
Table I. Patient baseline and disease characteristics.

\begin{tabular}{l} 
Feature \\
\hline Total, n (\%) \\
Median age, years (range) \\
Age, years, n (\%) \\
$\leq 50$ \\
$>50$ \\
Tumor size, cm, n $(\%)$ \\
$<2$ \\
$>2$ and $\leq 5$ \\
$>5$ \\
Differentiation, n $(\%)$ \\
High \\
Moderate \\
Poor
\end{tabular}

Adjuvant chemotherapy, n (\%)

Yes

No

Histological type, n (\%)

IDC

Other types

ATCC stage, n (\%)

I

II

III-IV

Lymph node status, n (\%)

No

Yes

Breast cancer subtype, n (\%)

Luminal A

Luminal B

HER-2+

Basal-like

p53 status, n (\%)

Negative

Positive

ER status, n (\%)

Negative

Positive

PR status, n (\%)

Negative

Positive

HER-2 status, n (\%)

Negative

Positive

Ki-67 status, n (\%)

Negative

Positive

Survival status, n (\%)

Deceased

Alive
Table I. Continued.

\begin{tabular}{lc}
\hline Feature & Patients \\
\hline Relapse status, n (\%) & \\
Yes & $40(13.07)$ \\
No & $266(86.93)$ \\
Median disease-free survival (range) & $69.41(2.14-75.02)$ \\
Median overall survival (range) & $68.27(3.85-75.02)$ \\
\hline IDC, invasive ductal carcinoma; ATCC, American Type Culture \\
Collection; HER-2, human epidermal growth factor receptor-2; ER, \\
estrogen receptor; PR, progesterone receptor. \\
\hline
\end{tabular}

Table II. Correlation of stromal Cav-1, cytoplasmic Cav-1 and EGFR in the total group.

$260(84.97)$

$26(8.49)$

$249(81.37)$

57 (18.63)

$276(90.20)$

30 (9.80)

63 (20.59)

192 (62.75)

51 (16.66)

152 (49.67)

154 (50.33)

145 (47.39)

119 (38.89)

$18(5.91)$

24 (7.81)

207 (67.65)

99 (32.35)

$110(35.95)$

196 (64.05)

59 (19.28)

247 (80.72)

$237(77.45)$

$69(22.55)$

48 (15.69)

258 (84.31)

56 (18.30)

250 (81.70)

\begin{tabular}{lcc}
\hline Variable & Stromal Cav-1 & EGFR \\
\hline Cytoplasmic Cav-1 & & \\
Spearman's correlation & -0.325 & 0.177 \\
P-value $^{\mathrm{a}}$ & $<0.001^{\mathrm{a}}$ & $0.002^{\mathrm{a}}$ \\
Stromal Cav-1 $^{\text {Spearman's correlation }}$ & & \\
P-value $^{\mathrm{a}}$ & & 0.039 \\
\end{tabular}

${ }^{\mathrm{a}} \mathrm{P}<0.05$; Cav-1, caveolin-1; EGFR, epidermal growth factor receptor.

Table III. Correlation of stromal Cav-1, cytoplasmic Cav-1 and EGFR in the chemotherapy group.

\begin{tabular}{lcc}
\hline Variable & Stromal Cav-1 & EGFR \\
\hline Cytoplasmic Cav-1 & & \\
Spearman's correlation & -0.272 & 0.181 \\
P-value $^{\mathrm{a}}$ & $<0.001^{\mathrm{a}}$ & $0.005^{\mathrm{a}}$ \\
Stromal Cav-1 $^{\text {Spearman's correlation }}$ & & \\
P-value $^{\mathrm{a}}$ & & 0.016 \\
\hline
\end{tabular}

${ }^{\mathrm{a}} \mathrm{P}<0.05$; Cav-1, caveolin-1; EGFR, epidermal growth factor receptor.

stromal Cav-1 was negatively correlated with cytoplasmic Cav-1 expression in tumor tissues of total patients group $(\mathrm{r}=-0.325$; $\mathrm{P}<0.001$; Table II). EGFR expression was positively correlated with cytoplasmic Cav-1 expression $(r=0.181$; $\mathrm{P}=0.005)$, but no correlation with stromal Cav-1 expression in tumor tissues was identified; however, low expression of stromal Cav-1 was positively correlated with cytoplasmic Cav-1 expression in tumor tissues of the total patients group $(\mathrm{r}=-0.272 ; \mathrm{P}<0.001$; Table III).

Clinical significance of combined marker EGFR/stromal Cav-1 expression in breast cancer tissues. Four patient subgroups were classified according to the combined expression 


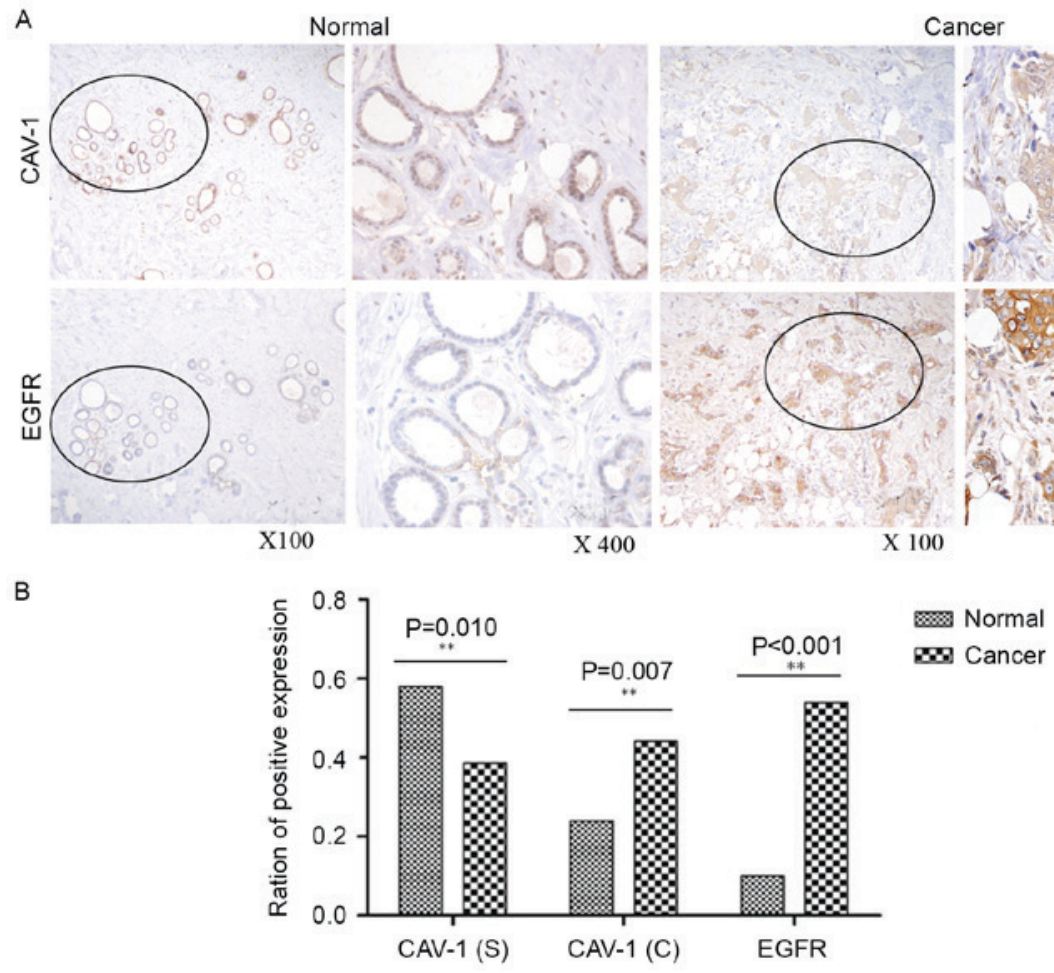

Figure 1. (A) IHC of protein expression in cancer tissues and adjacent normal tissues. High EGFR, high cytoplasmic Cav-1 expression and low stromal Cav-1 expression in tumor tissues compared with normal tissues. The magnification is indicated with the higher magnification images taken from the circled areas. (B) IHC of protein expression in tumor $(n=306)$ and normal tissues $(n=50)$. Compared with normal tissues, tumor tissues expressed significantly more stromal Cav-1 ( $\mathrm{P}=0.01)$, cytoplasmic Cav-1 ( $\mathrm{P}=0.007)$ and EGFR ( $\mathrm{P}<0.001)$. Cav-1 (C), cytoplasmic Cav-1; Cav-1 (S), stromal Cav-1; IHC, immunohistochemistry; EGFR, epidermal growth factor receptor; Cav-1, caveolin-1.
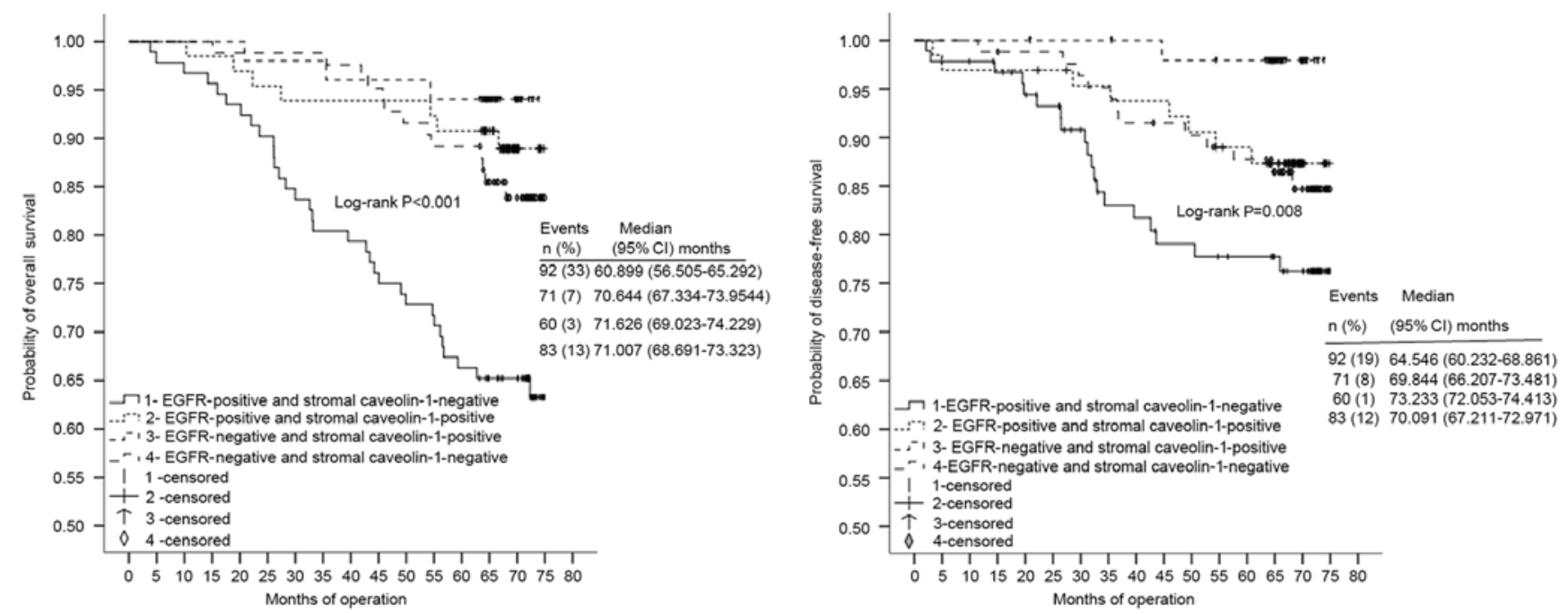

Figure 2. Line of overall survival and disease-free survival representing concurrent EGFR(+) and stromal caveolin-1(-) isolated separately from the other three lines $(\mathrm{P}<0.001$ and $\mathrm{P}=0.008$, respectively). EGFR, epidermal growth factor receptor; $\mathrm{CI}$, confidence interval.

status of EGFR and stromal Cav-1 (Fig. 2). For OS and DFS, patient tissues with concordant high EGFR $(\mathrm{P}<0.001)$ and low stromal Cav-1 $(\mathrm{P}=0.008)$ expression $(\mathrm{n}=92)$ were observed isolated from those of the other three groups, classified as low EGFR/high stromal Cav-1 ( $\mathrm{n}=60)$, high EGFR/high stromal Cav-1 (n=71) and low EGFR/low stromal Cav-1 ( $\mathrm{n}=83)$. To simplify the data and illustrate a mechanistic framework, the four groups were consolidated into Cluster A [EGFR(+) and stromal Cav-1(-), $\mathrm{n}=92$ ] and Cluster B [either EGFR(-) or stromal Cav-1(+), $n=214]$. Notably, there were significant associations with differentiation $(\mathrm{P}=0.041)$, p53 status $(\mathrm{P}=0.019)$ and $\mathrm{PR}$ status $(\mathrm{P}=0.036)$ for the Cluster A subgroup (data not shown).

OS univariate and multivariate analyses. The patients were divided into two further groups (adjuvant chemotherapy-treated patients, n=249; non-adjuvant chemotherapy-treated patients, $\mathrm{n}=57$ ) on the basis of whether they received adjuvant 


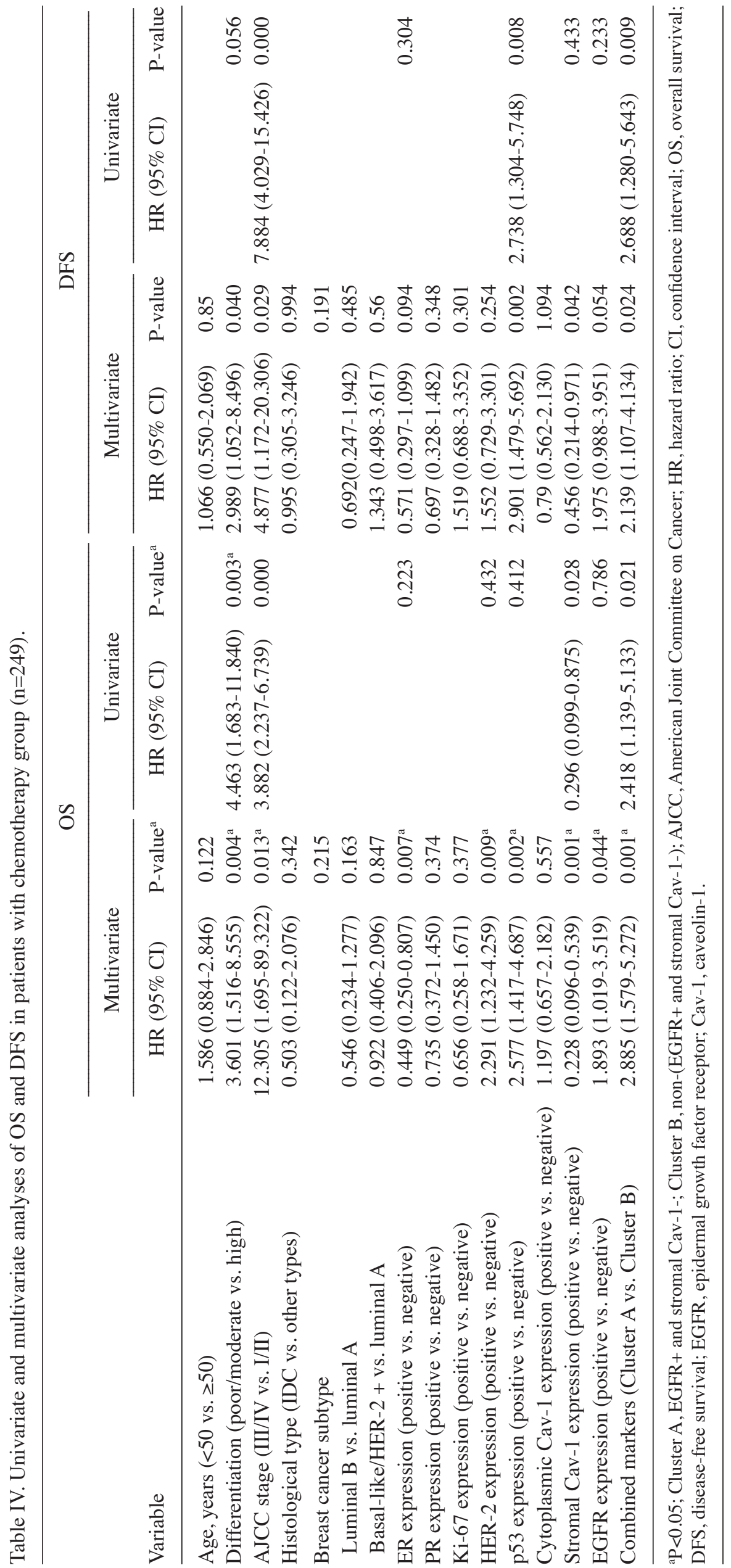




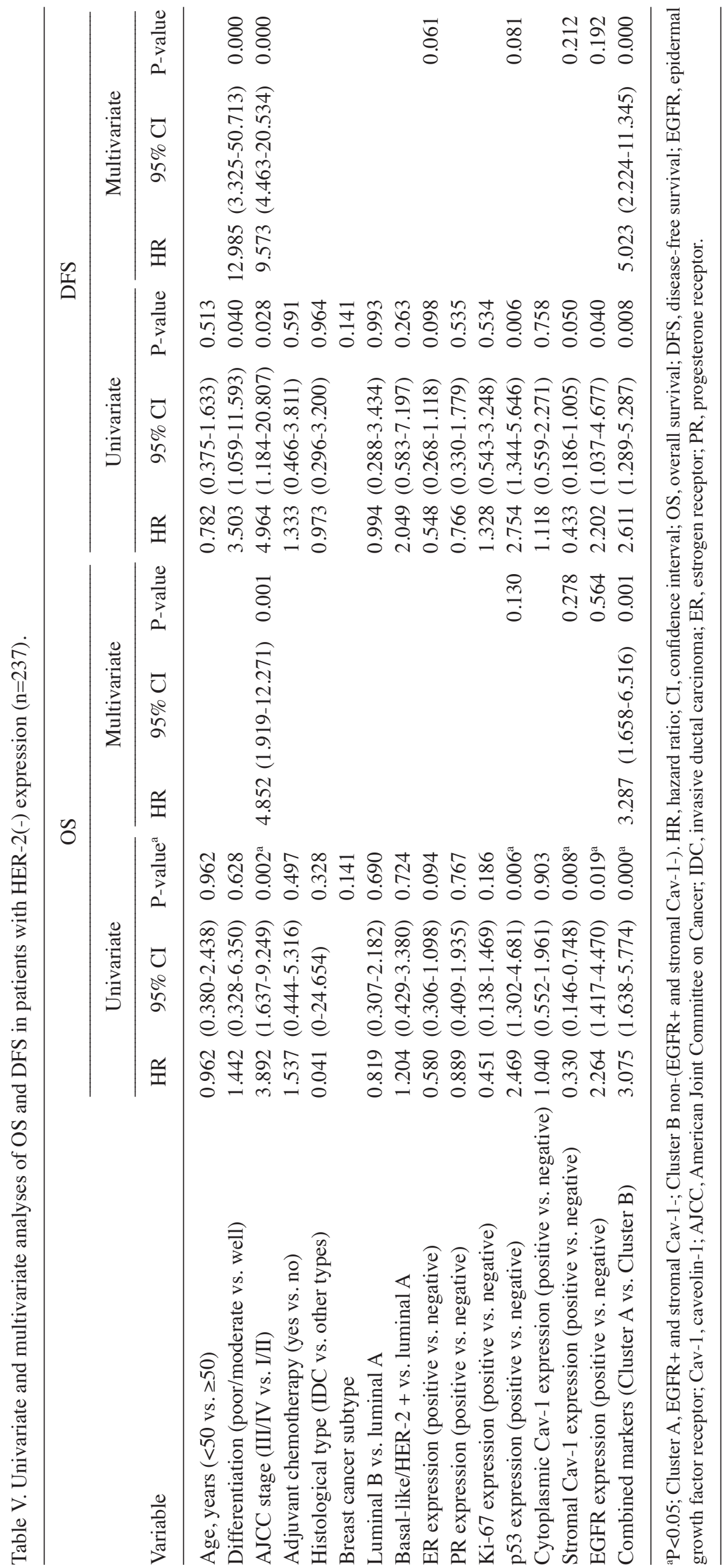



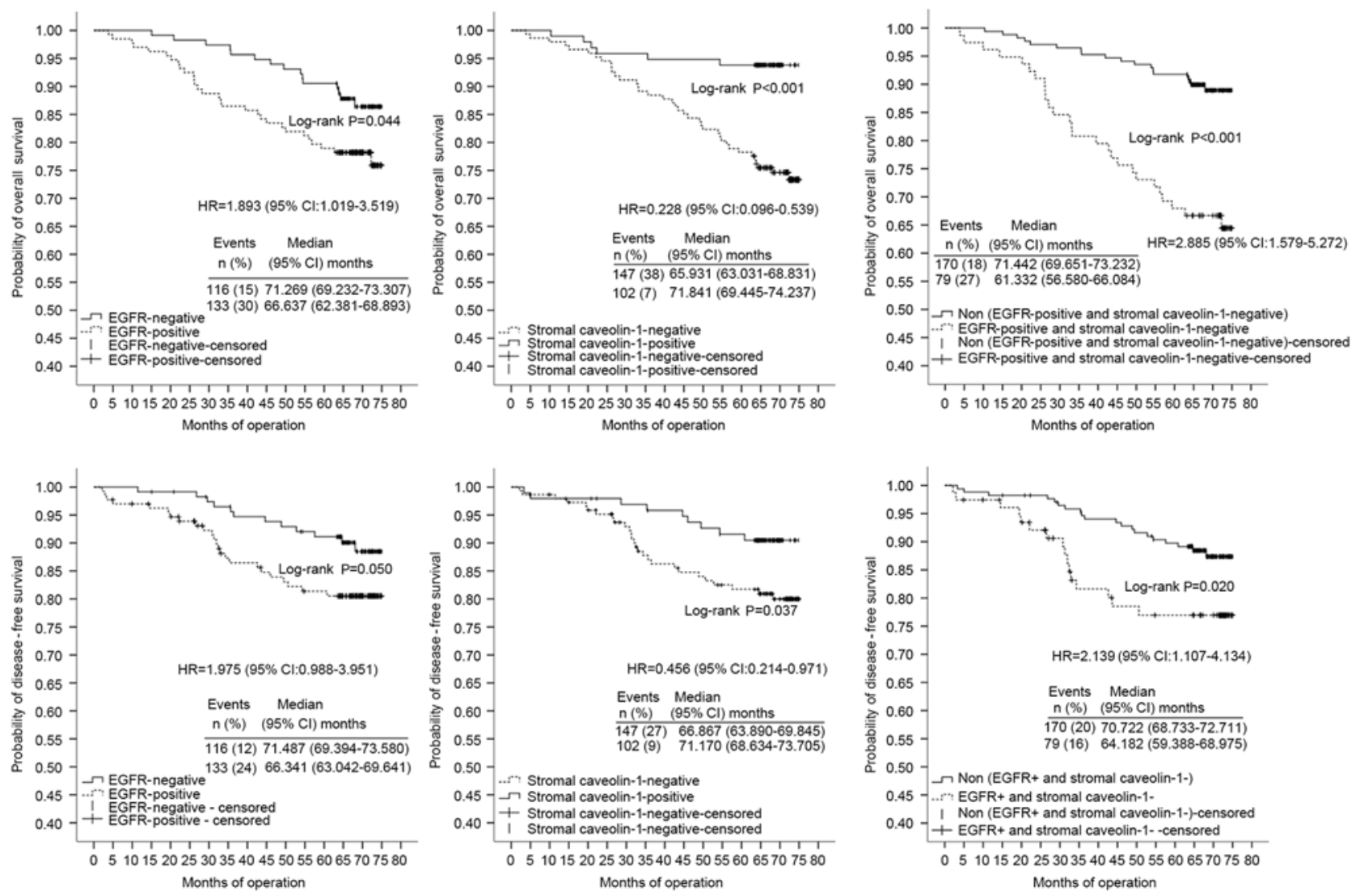

Figure 3. Kaplan-Meier estimator plots of overall survival and disease-free survival time distribution in association with $\mathrm{EGFR}(\mathrm{P}=0.044$ and $\mathrm{P}=0.050$, respectively), stromal Cav-1 $(\mathrm{P}<0.001$ and $\mathrm{P}=0.037$, respectively) and cluster (EGFR and stromal Cav-1) $(\mathrm{P}<0.001$ and $\mathrm{P}=0.020$, respectively) expression in patients with chemotherapy. EGFR, epidermal growth factor receptor; Cav-1, caveolin-1; CI, confidence interval; HR, hazard ratio.
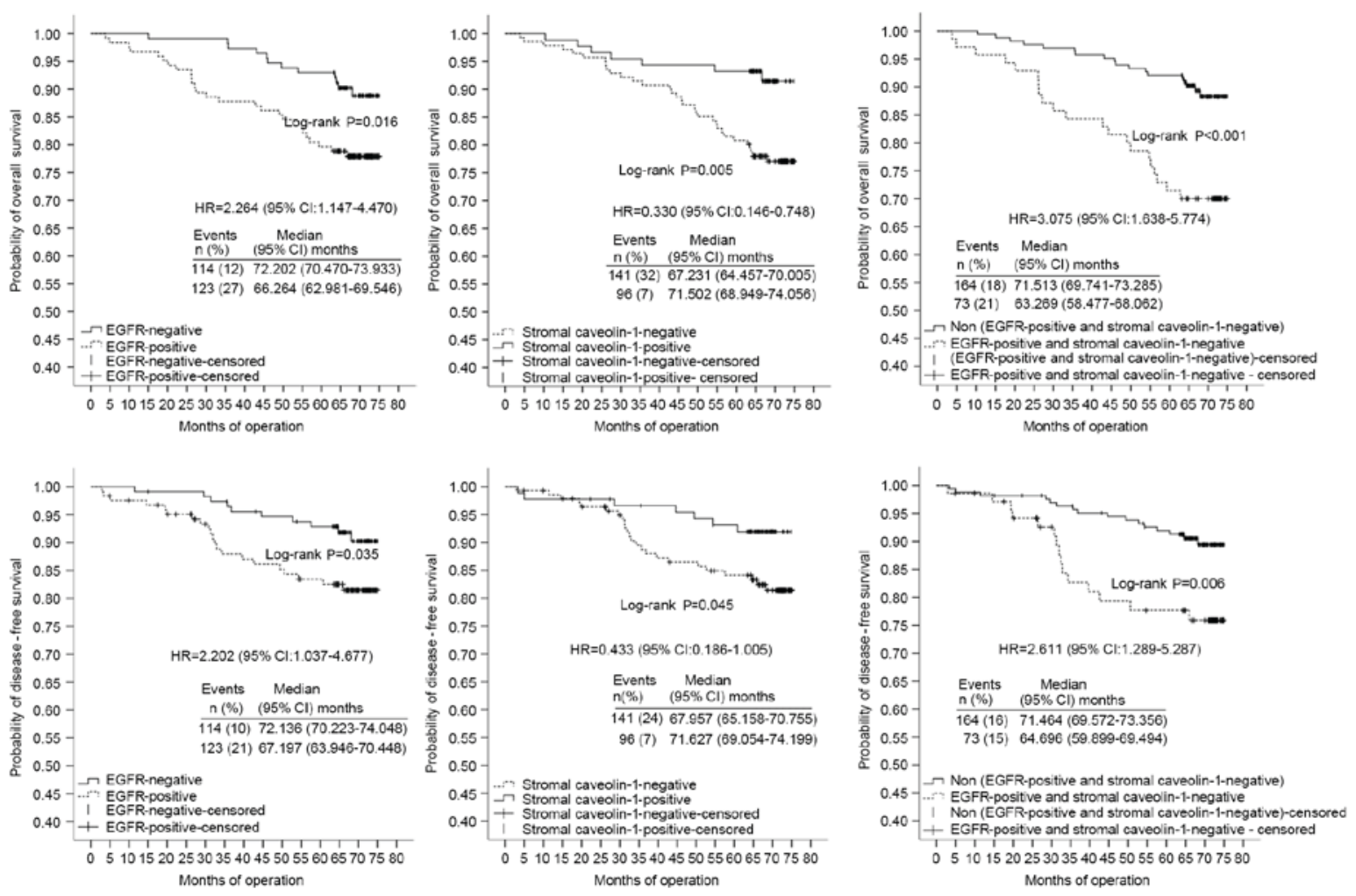

Figure 4. Kaplan-Meier estimator plots of overall survival and disease-free survival time distribution in association with $\mathrm{EGFR}(\mathrm{P}=0.016$ and $\mathrm{P}=0.035$, respectively), stromal Cav-1 ( $\mathrm{P}=0.005$ and $\mathrm{P}=0.045$, respectively) and cluster (EGFR and stromal Cav-1) $(\mathrm{P}<0.001$ and $\mathrm{P}=0.006$, respectively) expression in patients with human epidermal growth factor receptor 2(-) expression. EGFR, epidermal growth factor receptor; Cav-1, caveolin-1; CI, confidence interval; HR, hazard ratio. 
Table VI. Univariate and multivariate analyses of overall survival in patients with HER-2(+) expression $(\mathrm{n}=69)$.

\begin{tabular}{|c|c|c|c|c|c|c|}
\hline \multirow[b]{2}{*}{ Variable } & \multicolumn{3}{|c|}{ Univariate } & \multicolumn{3}{|c|}{ Multivariate } \\
\hline & HR & $95 \% \mathrm{CI}$ & P-value ${ }^{a}$ & HR & $95 \% \mathrm{CI}$ & P-value ${ }^{a}$ \\
\hline Age, years ( $<50$ vs. $\geq 50)$ & 0.962 & $(0.380-2.438)$ & 0.962 & & & \\
\hline Differentiation (poor/moderate vs. well) & 1.442 & $(0.328-6.350)$ & 0.628 & & & \\
\hline AJCC stage (III/IV vs. I/II) & 3.892 & $(1.637-9.249)$ & $0.002^{\mathrm{a}}$ & 4.852 & $(1.919-12.271)$ & $0.001^{\mathrm{a}}$ \\
\hline Adjuvant chemotherapy (yes vs. no) & 1.537 & $(0.444-5.316)$ & 0.497 & & & \\
\hline Histological type (IDC vs. other types) & 0.041 & $(0-24.654)$ & 0.328 & & & \\
\hline Breast cancer subtype & & & 0.141 & & & \\
\hline Basal-like /HER-2+ vs. luminal A vs. luminal B & 0.823 & $(0.270-2.502)$ & 0.731 & & & \\
\hline ER expression (positive vs. negative) & 0.626 & $(0.144-2.729)$ & 0.533 & & & \\
\hline PR expression (positive vs negative) & 0.950 & $(0.310-2.905)$ & 0.928 & & & \\
\hline Ki-67 expression (positive vs. negative) & 1.028 & $(0.428-2.469)$ & 0.951 & & & \\
\hline p53 expression (positive vs. negative) & 1.192 & $(0.458-3.099)$ & 0.719 & & & 0.081 \\
\hline Cytoplasmic Cav-1 expression (positive vs. negative) & 1.023 & $(0.377-2.775)$ & 0.964 & & & \\
\hline Stromal Cav-1 expression (positive vs. negative) & 0.237 & $(0.068-0.830)$ & $0.024^{\mathrm{a}}$ & & & 0.619 \\
\hline EGFR expression (positive vs. negative) & 1.712 & $(0.610-4.804)$ & 0.307 & & & \\
\hline Combined markers (Cluster A vs. Cluster B) & 4.627 & $(1.726-12.404)$ & $0.002^{\mathrm{a}}$ & 7.384 & $(2.522-21.714)$ & $0.000^{\mathrm{a}}$ \\
\hline
\end{tabular}

${ }^{\mathrm{a}} \mathrm{P}<0.05$; Cluster A, EGFR+ and stromal Cav-1-; Cluster B non-(EGFR+ and stromal Cav-1-). HR, hazard ratio; CI, confidence interval; EGFR, epidermal growth factor receptor; Cav-1, caveolin-1; ER, estrogen receptor; PR, progesterone receptor; AJCC, American Joint Committee on Cancer; IDC, invasive ductal carcinoma.
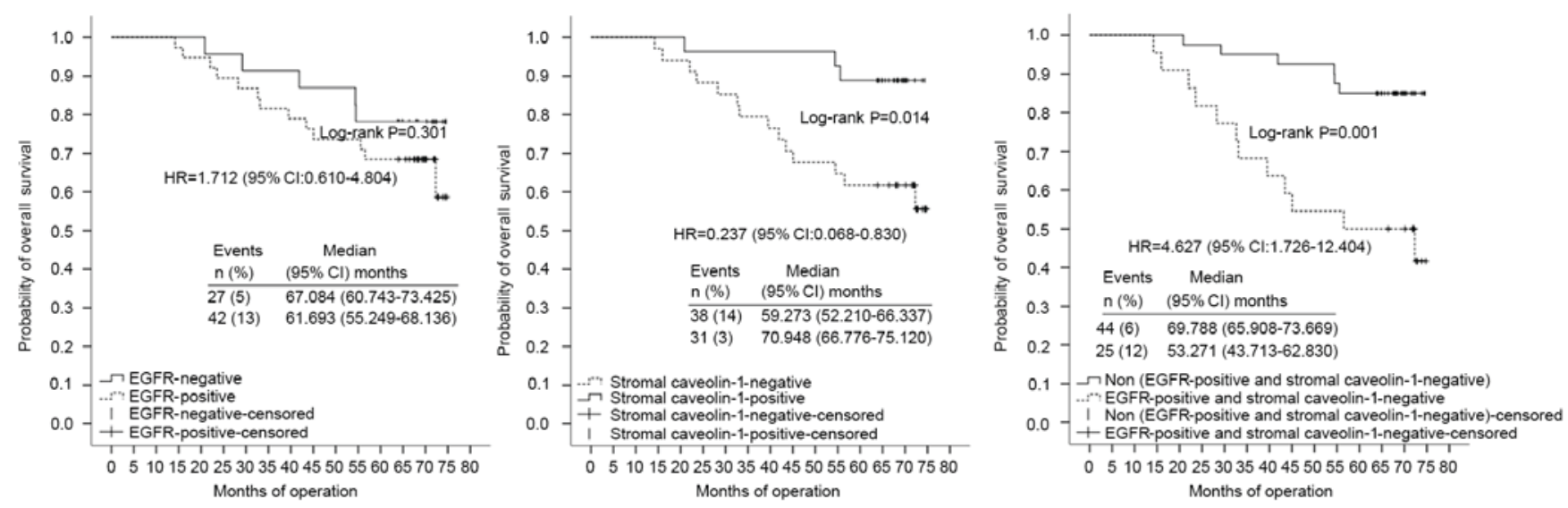

Figure 5. Kaplan-Meier estimator plots of overall survival time distribution in relation to EGFR $(\mathrm{P}=0.301)$, stromal Cav-1 $(\mathrm{P}=0.014)$ and cluster $(\mathrm{EGFR}$ and stromal Cav-1) $(\mathrm{P}=0.001)$ expression in patients with human epidermal growth factor receptor 2(-) expression. EGFR, epidermal growth factor receptor; Cav-1, caveolin-1; CI, confidence interval; HR, hazard ratio.

chemotherapy soon after surgical resection or not. In multivariate analyses using stratified Cox regression, OS rates of the adjuvant chemotherapy-treated patients were significantly lower in tissues with poor/moderate differentiation (HR, 4.463; 95\% CI, 1.683-11.840), high TNM clinical stage (HR, 3.882; 95\% CI, 2.237-6.739), stromal Cav-1(-) expression (HR, 0.296; 95\% CI, 0.099-0.875) or those in the Cluster A subgroup (HR, 2.418; 95\% CI, 1.139-5.133) (Table IV; Fig. 3). TNM clinical stage, p53 expression and combined expression of Cav-1 and EGFR markers were significant independent prognostic factors for DFS of the adjuvant chemotherapy-treated patients with HRs of 7.884 (95\% CI, 4.029-15.429), 2.738 (95\% CI, 1.304-5.748) and 2.688 (95\% CI, 1.280-5.643), respectively (Table IV;
Fig. 3). Notably, combined expression of Cav-1 and EGFR markers was the most marked independent prognostic factor in multivariate analysis, as presented in Fig. 3. For non-adjuvant chemotherapy-treated patients, EGFR, stromal Cav-1 and combined expression of Cav-1 and EGFR markers no significant correlation with OS in the multivariate analysis was identified.

Patients were divided into two groups on the basis of HER-2 and ER status. Multivariate analysis identified that differentiation, TNM clinical stage and combined markers were significant independent prognostic factors for OS of the HER-2(-) group $(\mathrm{n}=237)$ with HRs of 5.589 (95\% CI, 1.863-16.766), 11.326 (95\% CI, 1.545-83.025) and 3.287 (95\% CI, 1.658-6.516), respectively (Table V; 
Table VII. Univariate and multivariate analyses of overall survival in patients with estrogen receptor $(+)$ expression $(\mathrm{n}=196)$.

\begin{tabular}{|c|c|c|c|c|c|c|}
\hline \multirow[b]{2}{*}{ Variable } & \multicolumn{3}{|c|}{ Univariate } & \multicolumn{3}{|c|}{ Multivariate } \\
\hline & HR & $95 \% \mathrm{CI}$ & P-value ${ }^{a}$ & HR & $95 \% \mathrm{CI}$ & P-value \\
\hline Age, years (<50 vs. $\geq 50)$ & 1.929 & $(0.912-4.077)$ & 0.085 & 2.721 & $(1.225-6.004)$ & $0.014^{\mathrm{a}}$ \\
\hline Differentiation (poor/moderate vs. well) & 7.728 & $(2.657-22.473)$ & $0.000^{\mathrm{a}}$ & 13.309 & $(4.125-42.937)$ & $0.000^{\mathrm{a}}$ \\
\hline AJCC stage (III/IV vs. I/II) & 9.656 & $(1.312-71.069)$ & $0.026^{\mathrm{a}}$ & 4.241 & $(2.225-8.087)$ & 0.000 \\
\hline Adjuvant chemotherapy (yes vs. no) & 0.643 & $(0.273-1.513)$ & 0.312 & & & \\
\hline Histological type (IDC vs. other types) & 0.298 & $(0.040-2.192)$ & 0.234 & & & \\
\hline \multicolumn{7}{|l|}{ Breast cancer subtype } \\
\hline Basal-like/HER-2/luminal B vs. Luminal A & 0.630 & $(0.295-1.343)$ & 0.231 & & & \\
\hline Basal-like/HER-2(0) & - & - & - & - & - & - \\
\hline PR expression (positive vs. negative) & 0.770 & $(0.232-2.552)$ & 0.669 & & & \\
\hline Ki-67 expression (positive vs. negative) & 0.794 & $(0.238-2.648)$ & 0.708 & & & \\
\hline HER-2 expression (positive vs. negative) & 1.402 & $(0.533-3.689)$ & 0.494 & & & \\
\hline p53 expression (positive vs. negative) & 3.000 & $(1.426-6.311)$ & $0.004^{\mathrm{a}}$ & & & 0.176 \\
\hline Cytoplasmic Cav-1 expression (positive vs. negative) & 0.910 & $(0.429-1.934)$ & 0.807 & & & \\
\hline Stromal Cav-1 expression (positive vs. negative) & 0.349 & $(0.141-0.864)$ & $0.023^{\mathrm{a}}$ & 0.205 & $(0.077-0.547)$ & $0.002^{\mathrm{a}}$ \\
\hline EGFR expression (positive vs. negative) & 1.561 & $(0.720-3.382)$ & 0.259 & & & \\
\hline Combined markers (Cluster A vs. Cluster B) & 2.546 & $(1.211-5.355)$ & $0.014^{\mathrm{a}}$ & & & 0.543 \\
\hline
\end{tabular}

${ }^{\mathrm{a}} \mathrm{P}<0.05$; Cluster A, EGFR+ and stromal Cav-1-; Cluster B non-(EGFR+ and stromal Cav-1-). HR, hazard ratio; CI, confidence interval; EGFR, epidermal growth factor receptor; Cav-1, caveolin-1; HER-2, human epidermal growth factor receptor; PR, progesterone receptor; AJCC, American Joint Committee on Cancer; IDC, invasive ductal carcinoma.
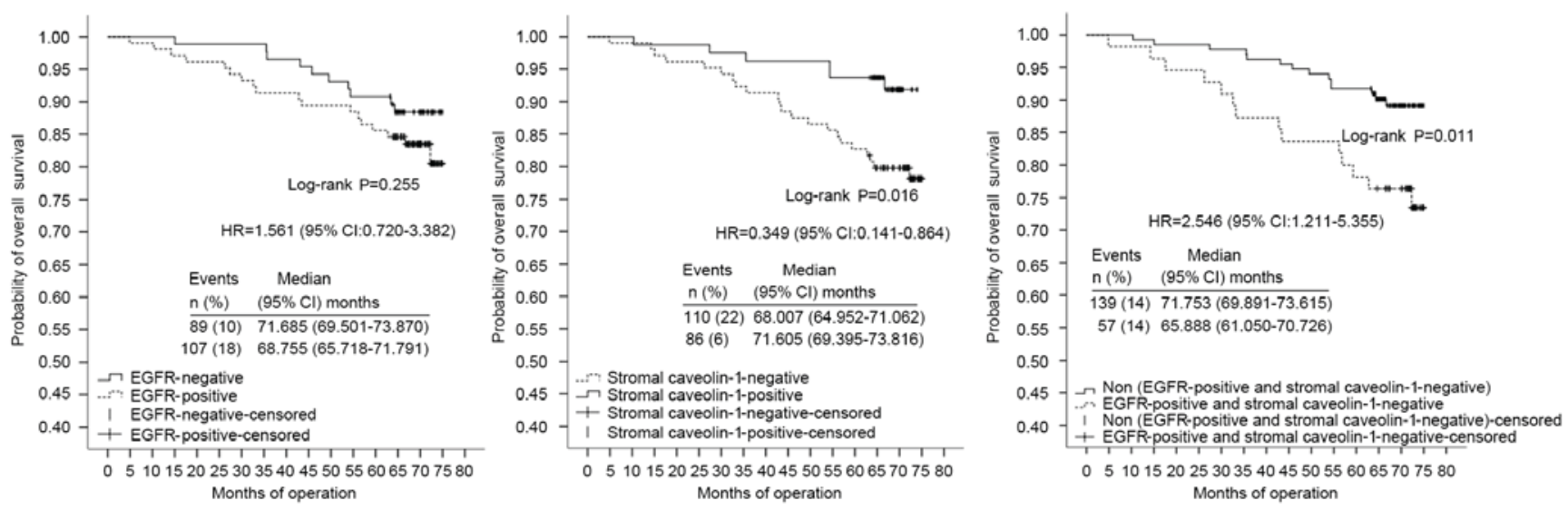

Figure 6. Kaplan-Meier estimator plots of overall survival time distribution in association with EGFR ( $\mathrm{P}=0.255)$, stromal Cav-1 ( $\mathrm{P}=0.016)$ and cluster (EGFR and stromal Cav-1) $(\mathrm{P}=0.011)$ expression in patients with human epidermal growth factor receptor-2(-) expression in patients with estrogen receptor $(+)$ expression. EGFR, epidermal growth factor receptor; Cav-1, caveolin-1; CI, confidence interval; HR, hazard ratio.

Fig. 4). Poor/moderate differentiation (HR, 12.985; CI 95\%, 3.325-50.713), high TNM clinical stage (HR, 9.573; 95\% CI, 4.463-20.534) and combined markers in Cluster A (HR, 5.023; 95\% CI, 2.224-11.345) were also confirmed as independent prognostic factors for low DFS of the HER-2(-) group (Table V; Fig. 4). High TNM clinical stage (HR, 4.852; 95\% CI, 1.919-12.271) and combined markers in Cluster A (HR, 7.384; 95\% CI, 2.522-21.714) were significant independent prognostic factors for OS in the HER-2(+) group ( $n=69)$ (Table VI; Fig. 5).

OS of the ER(+) group ( $\mathrm{n}=196)$ was significantly decreased in patients of younger age ( $<50$ vs. $\geq 50$ years; HR, 2.712;
95\% CI, 1.225-6.004) and in tumor tissues of poor/moderate differentiation (HR, 13.309; 95\% CI, 4.125-42.937), high TNM clinical stage (HR, 4.241; 95\% CI, 2.225-8.087) and stromal Cav-1(-) expression (HR, 0.205; 95\% CI, 0.077-0.547) (Table VII; Fig. 6). TNM clinical stage and combined markers were significant independent prognostic factors of OS of the ER(-) group ( $\mathrm{n}=110)$ with HRs of 3.631 (95\% CI, 1.768-7.456) and 5.020 (95\% CI, 2.250-11.200), respectively (Table VIII; Fig. 7). No significant correlation between EGFR, stromal Cav-1 and combined markers with DFS of ER(+) $(n=188)$ or HER-2 $(+)(n=62)$ groups were identified in the multivariate analysis. However, the rates for DFS of the ER(-) group 


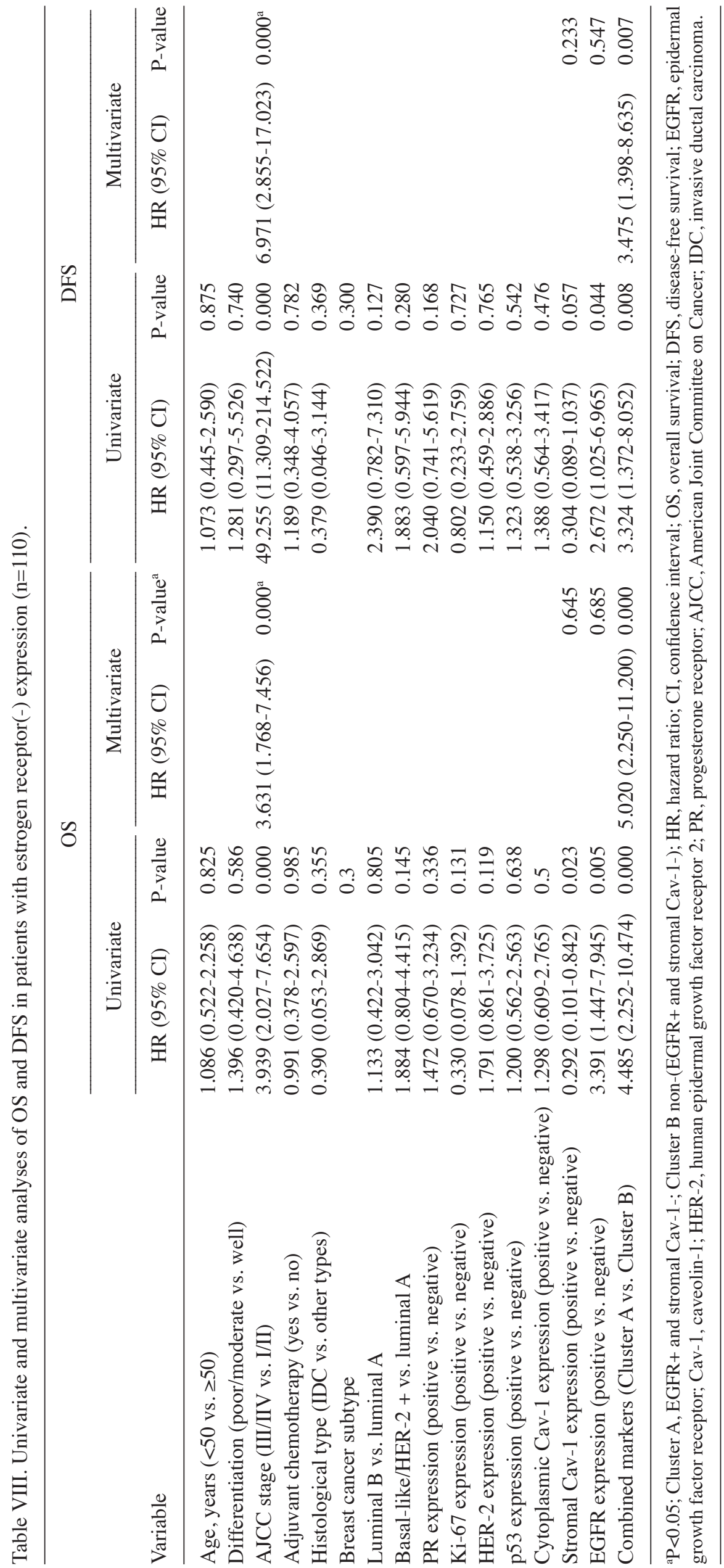



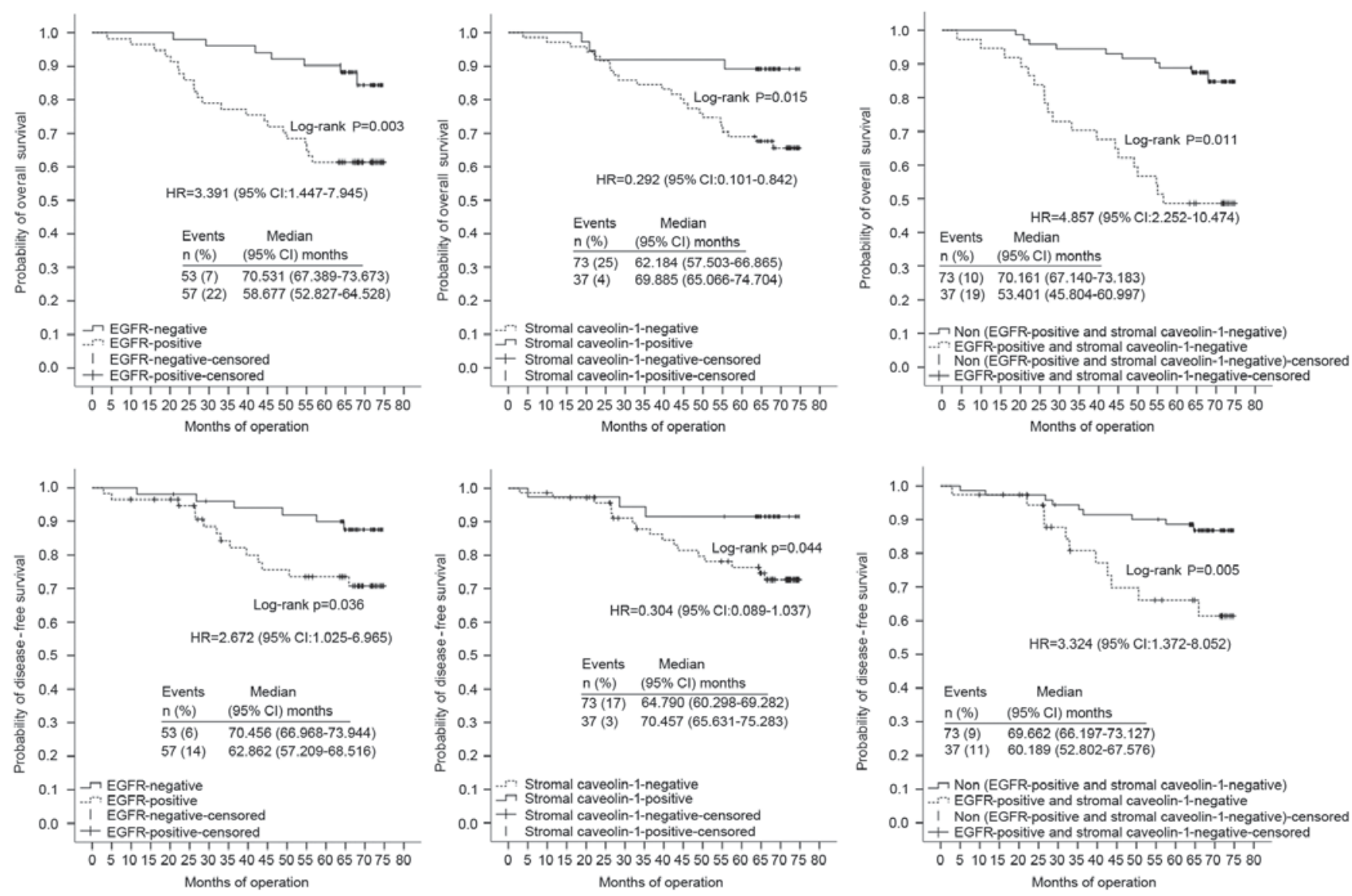

Figure 7. Kaplan-Meier estimator plots of overall survival and disease-free survival time distribution in association with $\mathrm{EGFR}(\mathrm{P}=0.003$ and $\mathrm{P}=0.036$, respectively), stromal Cav-1 ( $\mathrm{P}=0.015$ and $\mathrm{P}=0.044$, respectively) and cluster (EGFR and stromal Cav-1) $(\mathrm{P}=0.011$ and $\mathrm{P}=0.005$, respectively) expression in patients with estrogen receptor(-) expression. EGFR, epidermal growth factor receptor; Cav-1, caveolin-1; CI, confidence interval; HR, hazard ratio.

were significantly lower in tumor tissues of more advanced TNM clinical stage (HR, 6.971; 95\% CI, 2.855-17.023) and those under combined markers in Cluster A (HR, 3.475; 95\% CI, 1.398-8.635) (Table VIII; Fig. 7).

\section{Discussion}

Cav-1 is a primary scaffolding protein of the cell membrane whose abnormal stromal expression is associated with the occurrence, progression and prognosis of breast cancer $(5,13)$, and Cav-1 negatively regulates EGFRs $(17,31)$, further confirmed by data from the present study. In addition, it was revealed that Cav-1 is more effective as a breast cancer prognostic marker when its expression is combined with that of EGFR.

Multiple factors analysis of a series of variables revealed that, for patients in the ER(+) group, the expression of stromal Cav-1 alone is a significant prognostic marker of breast cancer. However, in the chemotherapy, HER-2(-), HER-2(+) and ER(-) groups, use of combined markers was more effective. Specifically, stromal Cav-1 expression combined with that of EGFR tends to have greater prognostic capacity than that of Cav-1 alone. Indeed, the data identified a consistent correlation among stromal Cav-1 and EGFR expression with clinical pathological features. This finding may be useful during the first step of prognostic screening as Cav-1 is readily detected in numerous breast cancer tumors.
Cav-1 is able to bind the signal transduction factor EGFR to regulate its tyrosine kinase activity and one of the notable findings is the ability of Cav-1 to regulate certain tyrosine kinase receptors (29). Inactivated EGFRs are clustered within caveolae and leave this lipid raft structure upon activation and raft internalization is regulated by Cav-1 scaffolds that indirectly regulate EGFR (28). In addition, oligomeric Cav-1 domains bind to inactive EGFR and prevent its activation (17). It was revealed that $\mathrm{Cav}-1$ in the parenchyma is negatively associated with stromal Cav-1 expression and positively correlated with EGFR expression. It has been demonstrated that Cav-1 is a tumor suppressor in breast cancer (32). The combined results of these previous studies and our those of the present study suggest that Cav-1 has marked biological and clinical significance for $\operatorname{EGFR(+)~breast~cancer,~and~}$ the combination of stromal Cav-1 and EGFR expression in breast cancer is an improved prognostic indicator compared with either individually in tumors with a number of different receptor and pathological features.

\section{Acknowledgements}

The present study was supported by the Natural Science Foundation (grant no. 81372785) and the Natural Science Foundation of Heilongjiang (grant no. ZD201316). The authors thank the Department of Pathology of Harbin Medical University, The Third Affiliated Hospital of Harbin Medical 
University and the Department of Medical Genetics of Harbin Medical University.

\section{References}

1. Liedtke C, Kersting C, Bürger H, Kiesel L and Wülfing P: Caveolin-1 expression in benign and malignant lesions of the breast. World J Surg Oncol 5: 110, 2007.

2. Parkin DM, Bray F, Ferlay J and Pisani P: Global cancer statistics, 2002. CA Cancer J Clin 55: 74-108, 2005.

3. Engelman JA, Zhang XL, Galbiati F and Lisanti MP: Chromosomal localization, genomic organization, and developmental expression of the murine caveolin gene family (Cav-1, -2 and -3). Cav-1 and Cav-2 genes map to a known tumor suppressor locus (6-A2/7q31). FEBS Lett 429: 330-336, 1998.

4. Engelman JA, Zhang XL and Lisanti MP: Genes encoding human caveolin-1 and -2 are co-localized to the D7S522 locus (7q31.1), a known fragile site (FRA7G) that is frequently deleted in human cancers. FEBS Lett 436: 403-410, 1998.

5. Okamoto T, Schlegel A, Scherer PE and Lisanti MP: Caveolins, a family of scaffolding proteins for organizing 'preassembled signaling complexes' at the plasma membrane. J Biol Chem 273: 5419-5422, 1998

6. Hnasko R and Lisanti MP: The biology of caveolae: Lessons from caveolin knockout mice and implications for human disease. Mol Interv 3: 445-464, 2003.

7. Engelman JA, Zhang X, Galbiati F, Volonte D, Sotgia F, Pestell RG, Minetti C, Scherer PE, Okamoto T and Lisanti MP: Molecular genetics of the caveolin gene family: Implications for human cancers, diabetes, Alzheimer disease, and muscular dystrophy. Am J Hum Genet 63: 1578-1587, 1998.

8. Zhang W, Razani B, Altschuler Y, Bouzahzah B, Mostov KE, Pestell RG and Lisanti MP: Caveolin-1 inhibits epidermal growth factor-stimulated lamellipod extension and cell migration in metastatic mammary adenocarcinoma cells (MTLn3). Transformation suppressor effects of adenovirus-mediated gene delivery of caveolin-1. J Biol Chem 275: 20717-20725, 2000.

9. Smart EJ, Graf GA, McNiven MA, Sessa WC, Engelman JA, Scherer PE, Okamoto T and Lisanti MP: Caveolins, liquid-ordered domains, and signal transduction. Mol Cell Biol 19: 7289-7304, 1999.

10. Koleske AJ, Baltimore D and Lisanti MP: Reduction of caveolin and caveolae in oncogenically transformed cells. Proc Natl Acad Sci USA 92: 1381-1385, 1995.

11. Quest AF, Gutierrez-Pajares JL and Torres VA: Caveolin-1: An ambiguous partner in cell signalling and cancer. J Cell Mol Med 12: 1130-1150, 2008.

12. Sloan EK, Ciocca DR, Pouliot N, Natoli A, Restall C, Henderson MA, Fanelli MA, Cuello-Carrión FD, Gago FE and Anderson RL: Stromal cell expression of caveolin-1 predicts outcome in breast cancer. Am J Pathol 174: 2035-2043, 2009.

13. El-Gendi SM, Mostafa MF and El-Gendi AM: Stromal caveolin-1 expression in breast carcinoma. Correlation with early tumor recurrence and clinical outcome. Pathol Oncol Res 18: 459-469, 2012

14. Witkiewicz AK, Dasgupta A, Sotgia F, Mercier I, Pestell RG, Sabel M, Kleer CG, Brody JR and Lisanti MP: An absence of stromal caveolin-1 expression predicts early tumor recurrence and poor clinical outcome in human breast cancers. Am J Pathol 174: 2023-2034, 2009.

15. Couet J, Sargiacomo M and Lisanti MP: Interaction of a receptor tyrosine kinase, EGF-R, with caveolins. Caveolin binding negatively regulates tyrosine and serine/threonine kinase activities. J Biol Chem 272: 30429-30438, 1997.

16. Lajoie P, Partridge EA, Guay G, Goetz JG, Pawling J, Lagana A, Joshi B, Dennis JW and Nabi IR: Plasma membrane domain organization regulates EGFR signaling in tumor cells. J Cell Biol 179: 341-356, 2007.
17. Park WY, Park JS, Cho KA, Kim DI, Ko YG, Seo JS and Park SC Up-regulation of caveolin attenuates epidermal growth factor signaling in senescent cells. J Biol Chem 275: 20847-20852, 2000.

18. Savage K, Lambros MB, Robertson D, Jones RL, Jones C, Mackay A, James M, Hornick JL, Pereira EM, Milanezi F, et al: Caveolin 1 is overexpressed and amplified in a subset of basal-like and metaplastic breast carcinomas: A morphologic, ultrastructural, immunohistochemical, and in situ hybridization analysis. Clin Cancer Res 13: 90-101, 2007.

19. Agelaki S, Spiliotaki M, Markomanolaki H, Kallergi G, Mavroudis D, Georgoulias V and Stournaras C: Caveolin-1 regulates EGFR signaling in MCF-7 breast cancer cells and enhances gefitinib-induced tumor cell inhibition. Cancer Biol Ther 8: 1470-1477, 2009.

20. Ferrero JM, Ramaioli A, Largillier R, Formento JL, Francoual M, Ettore F, Namer M and Milano G: Epidermal growth factor receptor expression in 780 breast cancer patients: A reappraisal of the prognostic value based on an eight-year median follow-up. Ann Oncol 12: 841-846, 2001.

21. Jorge SE, Kobayashi SS and Costa DB: Epidermal growth factor receptor (EGFR) mutations in lung cancer: Preclinical and clinical data. Braz J Med Biol Res 47: 929-939, 2014.

22. Sordella R, Bell DW, Haber DA and Settleman J: Gefitinib-sensitizing EGFR mutations in lung cancer activate anti-apoptotic pathways. Science 305: 1163-1167, 2004.

23. Salomon DS, Brandt R, Ciardiello F and Normanno N: Epidermal growth factor-related peptides and their receptors in human malignancies. Crit Rev Oncol Hematol 19: 183-232, 1995.

24. Lynch TJ, Bell DW, Sordella R, Gurubhagavatula S, Okimoto RA, Brannigan BW, Harris PL, Haserlat SM, Supko JG, Haluska FG, et al: Activating mutations in the epidermal growth factor receptor underlying responsiveness of non-small-cell lung cancer to gefitinib. N Engl J Med 350: 2129-2139, 2004.

25. Lee JC, Vivanco I, Beroukhim R, Huang JH, Feng WL, DeBiasi RM, Yoshimoto K, King JC, Nghiemphu P, Yuza Y, et al: Epidermal growth factor receptor activation in glioblastoma through novel missense mutations in the extracellular domain. PLoS Med 3: e485, 2006.

26. Lafky JM, Wilken JA, Baron AT and Maihle NJ: Clinical implications of the ErbB/epidermal growth factor (EGF) receptor family and its ligands in ovarian cancer. Biochim Biophys Acta 1785: 232-265, 2008

27. Koenders PG, Beex LV, Kienhuis CB, Kloppenborg PW and Benraad TJ: Epidermal growth factor receptor and prognosis in human breast cancer: A prospective study. Breast Cancer Res Treat 25: 21-27, 1993.

28. Mineo C, Gill GN and Anderson RG: Regulated migration of epidermal growth factor receptor from caveolae. J Biol Chem 274: 30636-30643, 1999.

29. Hoop CL, Sivanandam VN, Kodali R, Srnec MN and van der Wel PC: Structural characterization of the caveolin scaffolding domain in association with cholesterol-rich membranes. Biochemistry 51: 90-99, 2012.

30. Edge SB and Compton CC: The American Joint Committee on Cancer: The 7th edition of the AJCC cancer staging manual and the future of TNM. Ann Surg Oncol 17: 1471-1474, 2010.

31. Cohen AW, Razani B, Wang XB, Combs TP, Williams TM, Scherer PE and Lisanti MP: Caveolin-1-deficient mice show insulin resistance and defective insulin receptor protein expression in adipose tissue. Am J Physiol Cell Physiol 285: C222-C235, 2003.

32. Lee SW, Reimer CL, Oh P, Campbell DB and Schnitzer JE: Tumor cell growth inhibition by caveolin re-expression in human breast cancer cells. Oncogene 16: 1391-1397, 1998. 